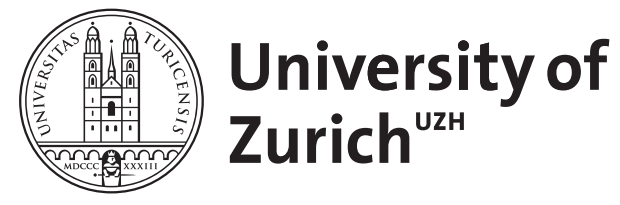

Zurich Open Repository and Archive

University of Zurich

University Library

Strickhofstrasse 39

CH-8057 Zurich

www.zora.uzh.ch

Year: 2013

Abstinence versus agonist maintenance treatment: an outdated debate?

Uchtenhagen, Ambros

DOI: https://doi.org/10.1159/000350373

Posted at the Zurich Open Repository and Archive, University of Zurich

ZORA URL: https://doi.org/10.5167/uzh-84287

Journal Article

Accepted Version

Originally published at:

Uchtenhagen, Ambros (2013). Abstinence versus agonist maintenance treatment: an outdated debate?

European Addiction Research, 19(6):283-286.

DOI: https://doi.org/10.1159/000350373 


\section{Abstinence versus agonist maintenance treatment: an outdated debate ?}

Ambros Uchtenhagen

After two decades of increasing acceptance and availability of agonist maintenance therapies, we hear more about limitations of this approach and about a new quest for abstinence oriented recovery. What is the state of these trends, and what are the facts and arguments?

Part of this development is already visible from the differential terminology in use: abstinence is perceived as instrumental for health and social improvements ('abstinence based therapy') or else as the final objective ('abstinence oriented therapy'). Recovery is used to describe a rehabilitation process in various shades ('back to normal'), but also to describe a socialisation process to model citizenship ('better than well'). And maintenance therapy goes as a temporary approach to engage those in treatment who otherwise cannot be reached ('maintenance to abstinence') or else as the treatment of a chronic condition ('unlimited maintenance').

The diverse terms mirror a dissatisfaction with the crude opposition abstinence versus maintenance, but in fact they present a new version of the old controversy: what are the goals of addiction treatment? Is the ultimate goal abstinence, or is it well-being with or without abstinence? In other words: "To what extent is your program making peoples' lives better, rather than simply suppressing alcohol/drug use? Structured assessment using appropriate brief wellbeing measures could facilitate discussions about broader life needs to be addressed. Further, insights from the literature on subjective wellbeing may inform services and interventions to help people establish happier, more meaningful lives within which addiction holds less attraction" (1).

The increasing acceptance and availability of agonist maintenance treatment is well documented: in Europe, the number of countries providing methadone maintenance increased from 7 in 1980 to 28 by 2005, and the number of countries providing buprenorphine maintenance rose within a few years to 21 (2). Globally, opioid maintenance treatment was available in 70 countries by 2009 (3). Even an increasing number of prison systems are offering MMT to prisoners (4). Driving forces were the HIV/Aids epidemic among drug injectors with increasing risks for the general population, and the ensuing need to bring as many injectors as possible into treatment arrangements.

Have the expectations been met? The research evidence is quite clear and has been well documented and reviewed. World Health Organisation has included methadone and buprenorphine, the two mainly used agonists in maintenance treatment, into the lists of essential medicines and summarised the state of research results $(5,6)$. Agonist maintenance treatment is an effective protector against blood borne infections in opioid injectors (by reducing injections of illicit or non-prescribed substances), and the increasing coverage of those out-of-treatment by offering maintenance treatment became a public health priority (7). In addition, one review mentions a reduction of HIV risk behaviours (needle sharing if injecting, number of sexual partners), further contributing to protection from blood borne infections (8). At the same time, maintenance therapies improve the health status, reduce addictive lifestyles and criminal involvement of those who are enrolled. Part of 
the positive effects are linked to sufficient retention. An extensive review of the evidence for policy guidance therefore includes the recommendation to provide agonist maintenance treatment even as a minimum standard (9).

It must be added, however, that the quality of treatment delivery is uneven, and many national guidelines for agonist maintenance suffer from inconsistencies, mirroring more the concerns about misuse of prescribing than the available evidence (10). Positive outcomes are linked to adequate practice rules; shortcomings have been documented, such as mortality risks during the induction period, and diversion to illicit use. Side-effects may be heart problems with higher dosages of methadone ('Torsade de pointes') or interactions with other medications, most of which are manageable. Insufficient dosage invites continued use of non-prescribed substances (9). Patient satisfaction may suffer from degrading attitudes and lack of competence in staff (11); such limitations stem more from service characteristics than from the medication $(12,13)$. Interestingly, poor quality maintenance treatment reduces the benefits, but may still have benefits (14).

The research evidence on the results of abstinence oriented treatment is less extensive - a review mentions a gap in evaluation research (15) - , but also quite clear. Detoxification without follow-up treatment suffers from high rates of relapse (including an increased risk for opoid overdose due to decreased tolerance); the results can be improved when accompanied by psychosocial interventions (16); according to this Cochrane systematic review however there is no evidence that detoxification can substitute for long-term treatment in the management of opiate addiction (16). Long-term abstinence oriented treatment is mostly provided in residential facilities of the Therapeutic Community (TC) type. TC research has been performed in a range of countries, notably in the USA (17). Some follow-up studies document the social and psychological outcomes of patients up to 12 years after their treatment in TCs. Long-term residential TCs are effective in reducing drug abuse and antisocial behaviour, particularly in opioid dependence, and the extent of improvement is directly related to retention in treatment (e.g. 17,18). However, most TC admissions do not complete the planned length of treatment. A recent systematic review of therapeutic effectiveness shows completion rates from 9 to $56 \%$. All studies showed that substance use decreased during TC, but relapse was frequent after TC. Treatment completion was the most predictive factor of abstinence at follow-up. Long-lasting benefits were uncertain (19). It must be added, that attempts to overcome low patient preference and high drop-out rates by enforced abstinence are doomed to failure from poor outcomes, not to mention the ethical problems involved (20).

Comparing abstinence-oriented treatment and agonist maintenance therapies is not frequently made by studies with randomised controlled design. A Cochrane review covered 13 RTC studies and found that methadone maintenance treatment had significantly better retention and more reduction in heroin use, in comparison to treatments without opioid substitution (21).

More information is available from multi-modality outcome studies with follow-ups of cohorts from drug-free treatment and maintenance programs. 12-year outcomes in the Drug Abuse Reporting Program DARP in USA showed no significant differences in males from methadone maintenance and therapeutic communities regarding daily opioid use or any opioid use, but a higher reduction in alcohol use and higher rates of employment in the TC group. Outcomes from out-patient drug-free programs were less favourable (18). A similar 
prospective comparative cohort study from the UK found, 4-5 years after intake, higher rates of abstinence from all drugs in patients from TCs compared to those from methadone maintenance. Reductions in regular heroin use, non-prescribed methadone and benzodiazepine use, in psychological health problems and suicidality, however, were similar in both groups. Acquisitive crime rates were comparatively lower in MMT patients after 2 years, in TC patients after $4-5$ years $(22,23)$.

What do these findings show? Mainly that both therapeutic approaches, drug-free residential and agonist maintenance treatments have long-term positive outcomes, when provided in regular services and following routine practices in indication and delivery. Differences in outcomes between the two modalities are minimal and may be due to different sample characteristics and/or service quality. No superiority of one or the other can be concluded.

Economic studies document lower costs per time unit for maintenance treatments, but the difference disappears with length of stay. The cost-benefit ratio is clearly in favour of both modalities.

On the other side, the limitations of both modalities show major differences: residential drugfree treatments have lower retention and contribute much less to an overall coverage of opoid addicts in need of treatment in a competitive therapeutic market where both are freely available. Maintenance treatments have a longer, eventually indefinite duration, including variable restrictions for patients. For an evidence based treatment planning at the system level, the consequence is to favour maintenance treatment in the interest of good coverage and public health, but with an adequate offer of drug-free treatment for those who are ready for it.

During the last years, a strict separation of drug-free and maintenance treatment started to be weakened. A new type of mixed approaches came forward. Therapeutic Communities started to accept clients on maintenance medication, and a specific concept was set up for an integration of pharmacotherapy and TC methods in a day treatment model (24). The focus is on maintenance patients with persisting problems of non-prescribed substance use, comorbidity and deficient social adaptation. Other target groups also come to the forefront: "Treatment in residential facilities, formerly the predominant approach to the treatment of heroin use in many European countries, is relatively less common nowadays, and the majority of opioid users are treated in outpatient settings. Residential services are, however, of growing importance in the care of elderly and long-term drug users with complex treatment needs because of the coexistence of serious somatic and psychological co-morbidity. The philosophy of inpatient facilities and the way they work have changed considerably over the years, in response to changing needs" (25).

Conclusion: in view of these findings, the controversial debate makes little sense; prejudice and invested interests have more weight in it than an appreciation of the facts. In an era of individualised medicine there is no argument against having multiple evidence based treatment options where individual planning can be tailored to patient risks and needs. Instead of discussing which modality is superior, the debate has evolved into plans how to make best use of both. This includes the introduction of good quality of services in general, by standards and training. Another key-word is integrated services in an organised network, covering the full range from harm reduction to structured treatment approaches (26). Another 
is an effort to introduce stepped-care models, starting with self-help and offering more intense treatment only if previous steps prove inadequate or inefficient, in an interest of making best use of available resources at the system level $(27,28)$. For the future development, an appropriate combination of the 'invisible hand' of a competitive treatment market and the 'visible hand' of an evidence-based official policy seems best in order to improve therapeutic chances for all in need, for their environment and for the public good.

\section{References}

$1 \quad$ Miller PG, Miller WR (2009). What should we be aiming for in the treatment of addiction? Editorial. Addiction 104:685-686

2 EMCDDA (2006). Annual Report: The State of the Drugs Problem in Europe, European Monitoring Centre on Drugs and Drug Addiction, Lisbon

3 Mathers BM, Degenhardt L, Ali H, Wiessing L, Hickmann M, Mattick RP et al (2010). HIV prevention, treatment and care services for people who inject drugs: a systematic review of global, regional and national coverage. Lancet 375:1914-1028

$4 \quad$ Hedrich D, Farrell M (2012). Opioid maintenance in European Prisons: is the treatment gap closing? Editorial. Addiction 107:461-463

5 WHO (2004a Proposal For The Inclusion Of Methadone In The WHO Model List Of Essential Medicines. World Health Organisation, Geneva

6 WHO (2004b). Proposal For The Inclusion Of Buprenorphine In The WHO Model List Of Essential Medicines. World Health Organisation, Geneva

$7 \quad$ Gowing L, Farrell M, Bornemann R et al. (2011). Substitution treatment of injecting opioid users for prevention of HIV infection. Cochrane Database of Systematic Reviews 2011, Issue 8, Art.Nr. CD004145

8 Veilleux JC, Colvin PJ, Anderson J et al (2010). A review of opiate dependence treatment : pharmacological and psychological interventions to treat opioid addiction. Clinical Psychology Review 30:155-166

9 WHO (2009). Guidelines for the Psychosocially Assisted Pharmacological Treatment of Opioid Dependence. World Health Organisation, Geneva

10 Uchtenhagen A, Ladjevic T, Rehm J (2005). Review of national and general guidelines for substitution treatment of opioid dependence. Working paper for World Health Organisation. Research Institute for Public Health and Addiction at Zurich University.

11 ATF (1999). Addiction Treatment Forum vol. VIII (www.atforum.com) 
12 Uchtenhagen A (2006). Patient satisfaction in methadone maintenance treatment. Working paper for World Health Organisation. Research Institute for Public Health and Addiction at Zurich University.

13 Notley C, Blith A, Maskrey V, Craig J, Holland R (2013). Treatment and Recorded Barriers to Recovery: a Qualitative Systematic Review. European Addiction Research (this issue)

14 Strang J, Babor T, Caulkins J et al. (2012). Drug policy and the public good: evidence for effective interventions. Lancet 379:71-83

15 Broekaert E, Raes V, Kaplan CD, Coletti M (1999). The Design and Effectiveness of Therapeutic Community Research in Europe: An Overview. European Addiction Research 5:21-23

16 Amato L., Minozzi S., Davoli M. et al. (2011). Psychosocial and pharmacological treatments versus pharmacological treatments for opioid detoxification. Cochrane Database of Systematic Reviews: 2011, 9

17 De Leon G, Wexler H (2009). The Therapeutic Community for Addictions: An Evolving Knowledge Base. Journal of Drug Issues 39:167-178

18 Simpson DD, Sells SB (1990). Opioid Addiction and Treatment: A 12-Year FollowUp. Krieger, Malabar FA

19 Malivert M, Fatséas M, Denis C, Langlois E, Auriacombe M (2012). Effectiveness of Therapeutic Communities : A Systematic Review. European Addiction Research 18:1-11

20 Hall W, Babor T, Edwards G, Laranjeira R, Marsden J, Miller P, Obot I, Petry N, Thamarangsi T, West R (2012). Compulsory detention, forced detoxification and enforced labour are not ethically acceptable or effective ways to treat addiction. Editorial. Addiction 107:1891-1893

21 Mattick RP, Breen C, Kimber J, Davoli M (2009). Methadone maintenance therapy versus no opioid replacement therapy for opioid dependence. Cochrane Database Systematic Reviews 2009 Jul 8;(3):CD002209.pub2

22 Gossop M, Marsden J, Stewart D (2001a). NTORS After Five Years. The National Treatment Outcome Research Study. National Addiction Centre, London

23 Gossop M, Marsden J, Stewart D, Kidd T (2001b). The National Treatment Outcome Research Study (NTORS): 4-5 year follow-up results. Addiction 98:291-303

24 De Leon G (2003). Therapeutic Community nd Methadone Maintenance (Passages). A case illustration of an integrated Treatment Approach. In Waal H, Haga E (Eds.) Maintenance Treatment of Heroin Addiction, pp. 315-320. Cappelen, Oslo 
25 EMCDDA (2007). Annual Report : The State of the Drugs Problem in Europe, European Monitoring Centre on Drugs and Drug Addiction, Lisbon

26 Stevens A, Hallam C, Trace M (2006). Treatment for dependent drug use. A guide for policymakers. Beckley Foundation, London

27 Mee Lee D (2006). Development and Implementation of Patient Placement Criteria. New Developments in Addiction Treatment. Academic Highlights. Journal of Clinical Psychiatry 67:11:1805-1807

28 Schippers GM, Broekman TG, Buchholz A, Koeter MWJ, Van den Brink W (2010). Measurements in the Addictions for Triage and Evaluation (MATE): an instrument based on the World Health Organisation family of international classifications.

Addiction 105:862-871 